EPiC Series in Engineering
Volume 3, 2018, Pages 2368-2374
HIC 2018. 13th International
Conference on Hydroinformatics

\title{
Real-Time Flood Forecasting and Regulation System of Poyanghu Lake Basin in China
}

\author{
Xiaoming Jiang ${ }^{1,2}$, Xiaoyan $\mathrm{He}^{1,2}$, Liuqian Ding ${ }^{1,2}$, Jiren $\mathrm{Li}^{1,2}$, Hui $\mathrm{Li}^{1,2}$, \\ Fuxin Chai ${ }^{1,2}$, Guangyuan Kan ${ }^{1,2}$, Zhongbo Zhang ${ }^{1,2}$, Fan Wang ${ }^{1,2}$, Minglei$$
\operatorname{Ren}^{1,2}
$$ \\ ${ }^{1}$ China Institute of Water Resources and Hydropower Research, Beijing, China \\ ${ }^{2}$ Research Center on Flood \& Drought Disaster Reduction of the Ministry of Water Resource, \\ Beijing, China \\ jiangxm@iwhr.com
}

\begin{abstract}
The design and development of Flood Forecasting and Regulation System (FFRS) is an important part of non-structural measures for flood mitigation, and Browser/Server $(\mathrm{B} / \mathrm{S})$ system based on WEB technology is one of the main directions of the system development. The framework of FFRS based on B/S system is introduced in this paper, which includes four levels, i.e. the database level, application support platform level, the application level and the user level. The framework can provide several functions, such as flood situation analysis, flood forecasting, flood regulation and system management, which has been used for the FFRS development of Poyanghu Lake Basin in China as technical support for decision making of local flood control. Currently, the system covers almost 102 flood forecast points and 37 reservoirs, for which flood forecasts and regulations are accessible online. This work would also be demonstration for other locations.
\end{abstract}

\section{Introduction}

Modern science and technology, such as information processing, network communication, software engineering, are fully used to establish human-computer interactive real-time Flood Forecasting and Regulation System (FFRS), which can quantitatively forecast flood control situation in the whole and provide scientific basis and technical support for the flood control decision-making ${ }^{[1-2]}$.

Poyanghu Lake is the largest fresh-water lake in China and connects to the Yangzi River. Poyanghu Lake basin covers an area of nearly $160,000 \mathrm{~km}^{2}$, including Poyanghu Lake and 5 rivers (Ganjiang River, Fuhe River, Xinjiang River, Raohe River and Xiuhe River) as shown in Figure 1. The average annual rainfall of Poyanghu Lake basin is $1400-1900 \mathrm{~mm}$, and runoff in the area is generated mainly by 
local rainfall during April to June, which can possibly be very intense and may cause severe flooding in the area, so it is necessary for Poyanghu Lake basin to establish a real-time FFRS.

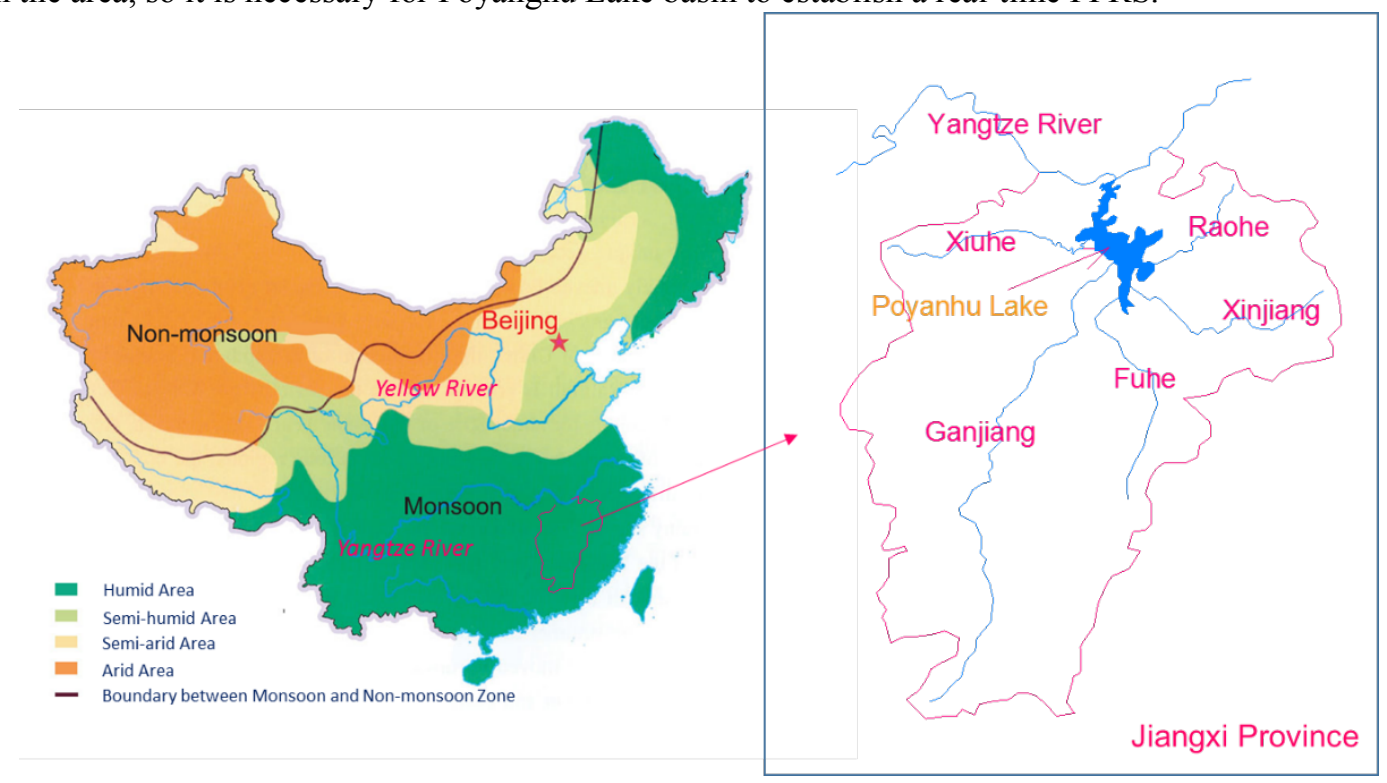

Figure 1: Poyanghu Lake Basin in China

In this paper, a real-time FFRS based on Browser/Server (B/S) system was designed to achieve the prediction and guard against of flood disasters in Poyanghu Lake basin. The system employs a multitiered architecture, and involves the functions of flood situation analysis, flood forecasting, flood regulation and system management, covering almost 102 flood forecast points and 37 reservoirs. The FFRS has been online for 3 years and taken an important role in local flood management.

\section{Material and methods}

The gauge stations, ranging from rainfall and meteorological parameters over soil moisture to water levels and discharges, have grown to an operational network in Poyanghu Lake basin .The local government maintains more than 4000 rain gauges across the basin, and the rain gauge network is sufficiently dense to provide the hydrologic models with reasonable rainfall estimates. Numerical weather models (NWM) by China Meteorological Administration provides quantitative precipitation forecasts (QPF) in 7 days. Time series of evaporation, gauged and forecasted rainfall are made of $10 \mathrm{~min}$, $30 \mathrm{~min}, 1 \mathrm{~h}, 3 \mathrm{~h}$ and $6 \mathrm{~h}$ interval, which are used to feed the hydrologic models that convert this input to discharge time series.

The study area belongs to subtropical humid monsoon climate zone, so the Xin'anjiang hydrological model, applicable to watersheds in the humid regions ${ }^{[3-4]}$, is used for modelling rainfall-runoff process. As a semi-distributed conceptual model, Xin'anjiang hydrological model separates each watershed of one forecast point into several sub-catchments. The evapotranspiration, runoff generation, and flow concentration computations are then carried out for each sub-catchment, and Muskingum successive routing method is used to link flood of each sub-catchment to the watershed outlet. The basic structure of the Xin'anjiang model is demonstrated in Figure 2. 


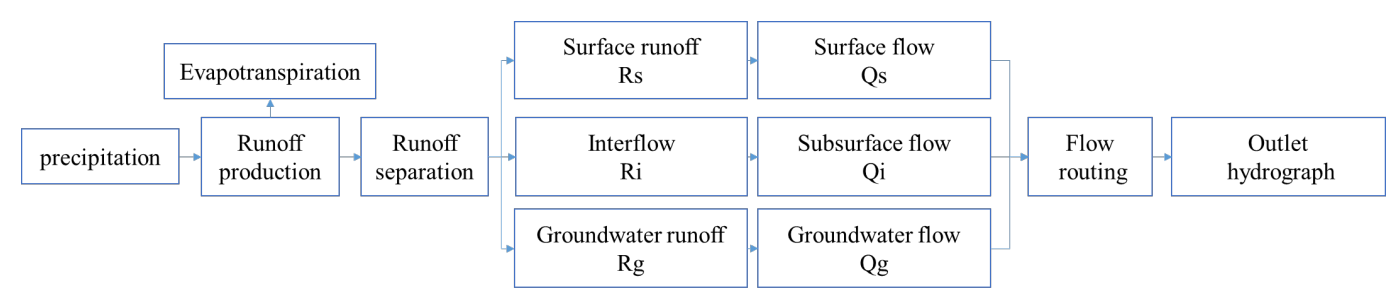

Figure 2: Xin'anjiang model flow chart ${ }^{[4]}$

The Xin'anjiang model parameters are optimized by the SCE-UA ${ }^{[5]}$. SCE-UA is an effective and robust optimization technique for calibrating watershed hydrological models by locating the global "best" parameter values stably and robustly. Historic hydrologic data from 2008 to 2013 were used for calibrating the presented hydrological model. According to the standard for hydrological information and hydrological forecasting of China, the peak flow relative error (PFRE), peak flooding time error (PFTE), and Nash-Sutcliffe coefficient of efficiency (NSCE) for 102 forecast points achieve the requirements of external release.

For some reservoirs, flood regulation should be considered after inflow forecasting. As one of the most efficient measures for flood control and conservation, flood regulation plays an important role in flood management. In general, the reservoir operation is carried out using regulation rules. But during flood season the reservoir operator always accord to the reservoir allowed maximum water level or outflow, or the estimated experience outflow value, to calculate optimized outflow curves and reservoir level variation, and choose the best operation scheme.

\section{Flood forecasting and regulation system}

The overall goal of this system design is to develop an interactive, practical, standard and safe flood forecasting and regulation system. The system framework is shown in Figure 3. 


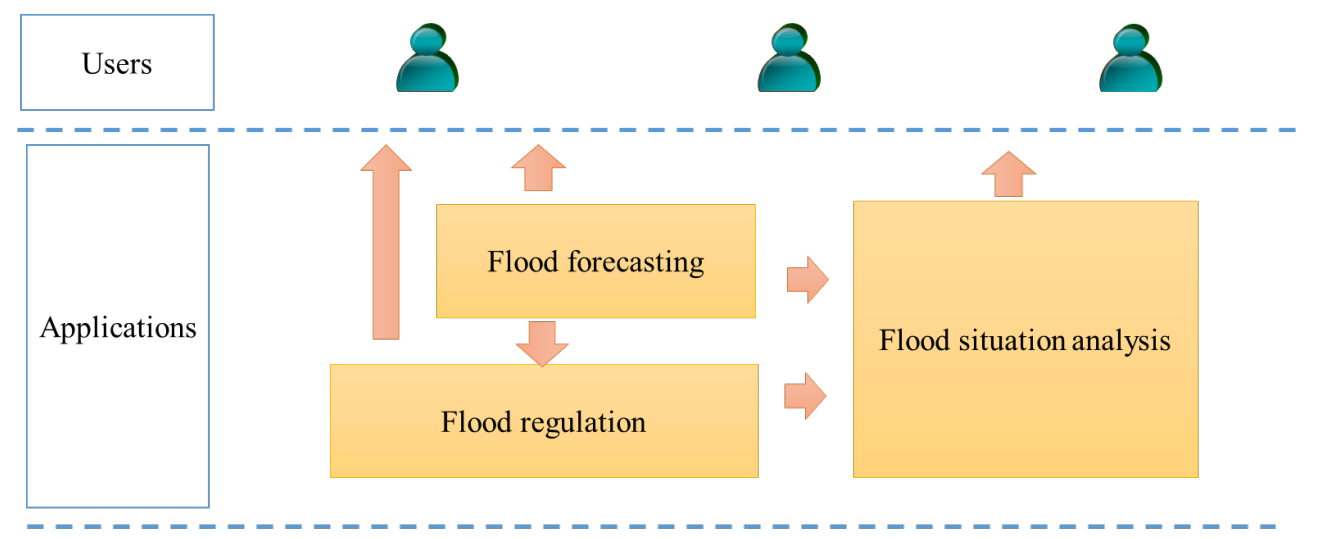

Application support platform

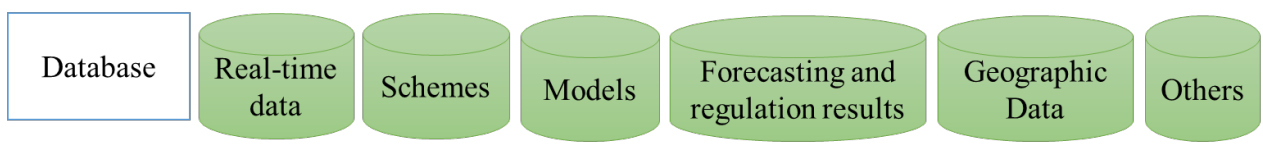

Figure 3: system framework

(1) Database level

Database is used by application support platform as the repository of the entire system. The FFRS synchronizes its real-time data with the central database in provincial hydro-information centre, to which all measurements of gauge stations are retrieved by data acquisition software. The FFRS database also stores forecasting schemes, models, forecasting and regulation results, and Geographic data.

(2) Application support platform level

Application support platform contains components that work together to solve business logic for applications level below, such as data preparation, web service, single sign on, and I/O buffering.

(3) Applications level

A. Flood situation analysis, as the support of flood forecasting, mainly provides the query and analysis of meteorological, rain, river, and engineering conditions and the publishing of flood forecasting results.

B. Flood forecasting is the core of the whole system, including real-time forecasting, forecasting program preparation, and management of results. A multi-level flood forecasting framework is designed. On the basis of traditional single-station forecasting model, mature single-station flood forecasting scheme is used in the automatic forecasting and river forecasting, and the efficiency of flood forecasting can be improved. The modularization method of forecasting scheme preparation is analysed. A standardized data interface definition is proposed for the same input and output elements of the forecasting model. The commonly-used empirical methods in China has been classified to build the database of experience method, which can construct multi-variable correlation relation, select stations, and search forecast maps.

C. Flood regulation is based on the inflow forecasting results. Reservoir operation scheme is made and simulated and the proper scheme would be adopted through comparisons.

(4) Users level 
In this level, Java Servlets are employed to deal with user interfaces and user interaction, and the hierarchical management mode of the system is designed to satisfy different levels of users, meet their functional needs, and avoid multi-version development. The user roles and menu management can be configured and extended.

\section{Results and discussion}

The Poyanghu Lake FFRS has been online since April, 2014. The system was deployed in two places (Figure 4) - provincial Office of flood control and drought relief headquarters (OFCDRH) and Hydrological bureau(HB), providing services more than 200 people online at the same time. The users involves hydrologist, reservoir managers and officials from provincial and municipal OFCDRH and $\mathrm{HB}$, and can easily runs an application from an internet browser on any computer that has a browser because of the $\mathrm{B} / \mathrm{S}$ architecture.

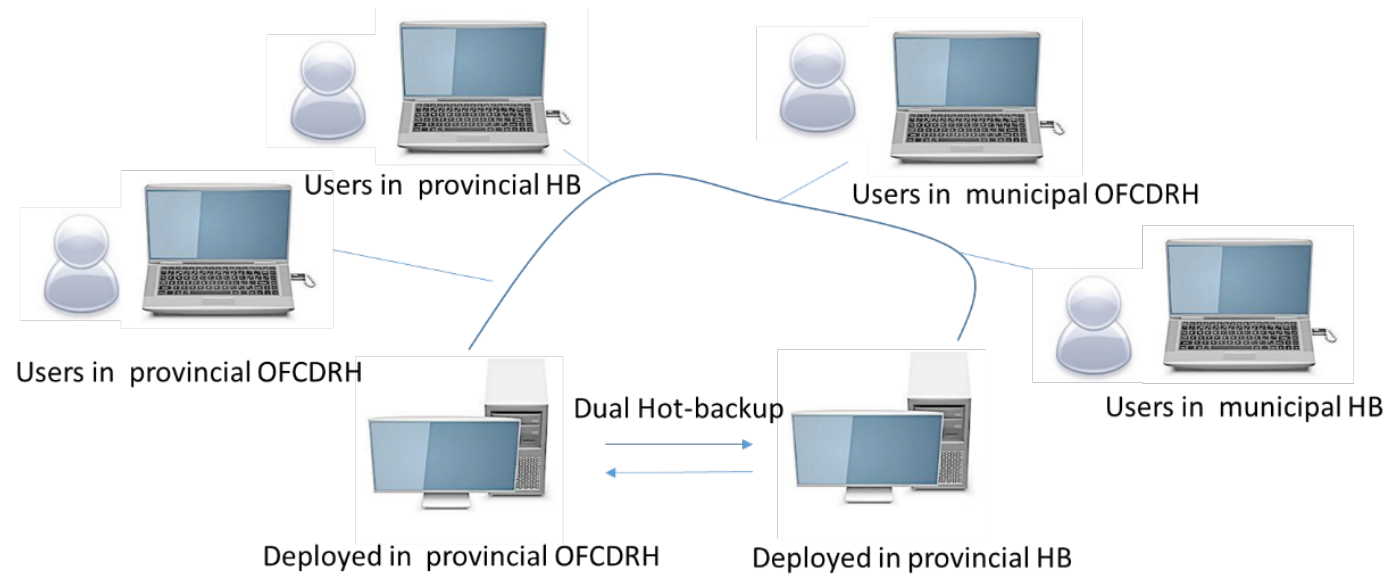

Figure 4: system deployment

The system can extract a catchment for the new forecast points based on DEM and establish its Xin'anjiang forecasting model. The parameters are calibrated first by daily procedure, providing status variables for the flood-event calibration next. The system carries out automatic forecasting every 1 hour or any other value the user set. (The model calibration and forecasting results is shown in Figure 5.) The Poyang Lake flood level is calculated by the statistical analysis of historical data of water level and discharge of seven inlets and one outlet of Poyang Lake.

The system can provide regulating services of 37 reservoirs concerned by provincial OFCDRH which is responsible for reservoir regulation business. Joint operation and united management of reservoir group in some rivers are implemented (Figure 6).

In the future, Deep learning methods will be used to analysis the increasingly monitoring data. The FFRS will establish its own cloud platform to store database and models, and integrate hydrometeorological model for extended forecast period. 


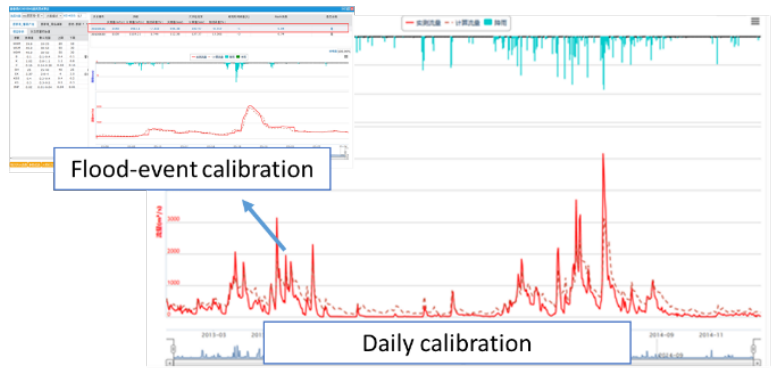

(a) Model calibration

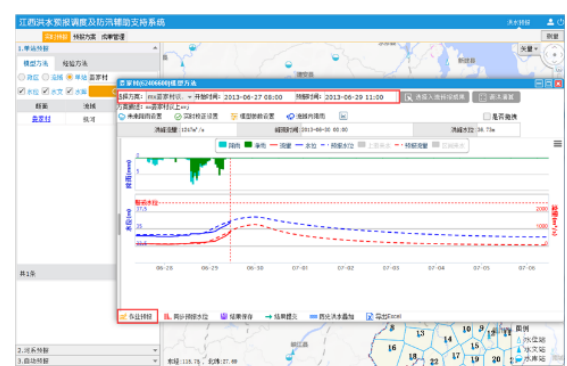

(b) Forecasting results

Figure 5: Model calibration and forecasting results

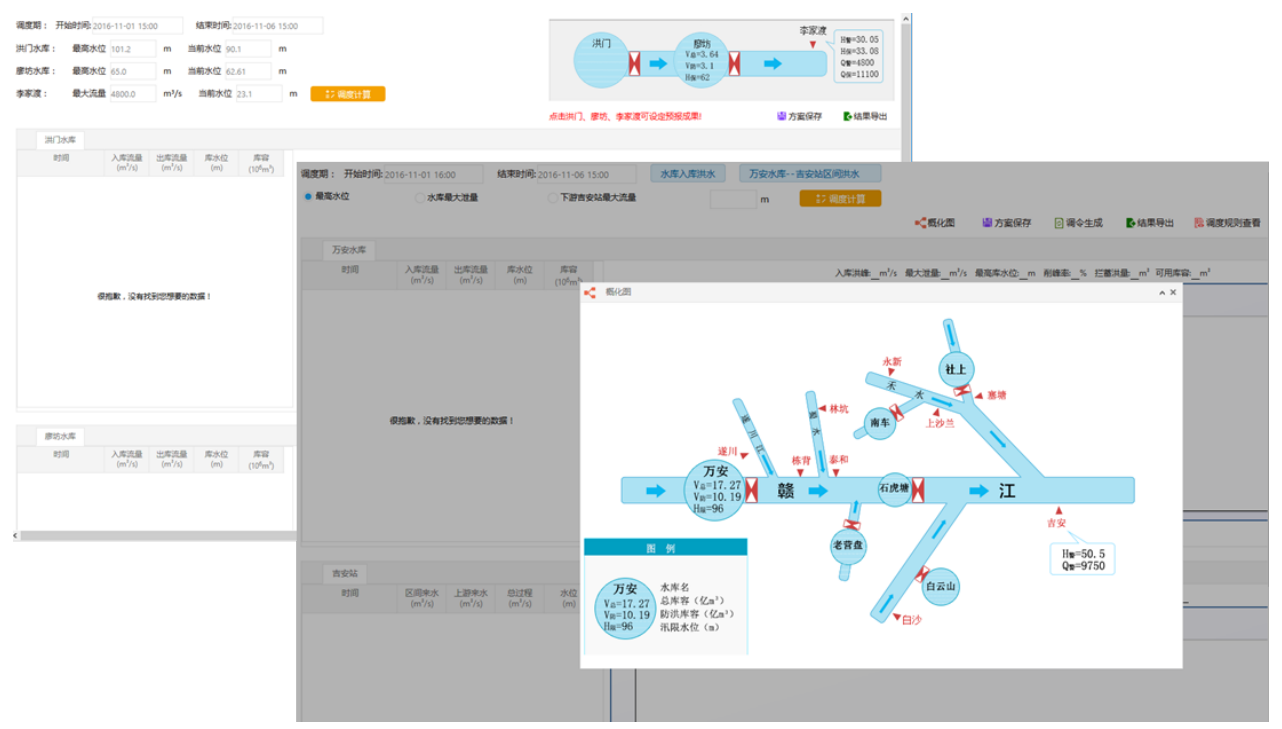

Figure 6: Joint operation of cascade reservoir in Fuhe River

\section{Conclusions}

In this paper, according to the flood forecasting and regulation needs of the Poyanghu Lake basin in China, FFRS based on B/S system has been developed to support for the local flood control decision making. The Xin'anjiang model, the rainfall runoff empirical model and the correlation diagram method are used to demonstrate the functions of program preparation, the single-station forecasting, the reservoir flood forecasting and the flood regulation calculation, etc. The design can be extended to the flood control command headquarters and hydrological departments of catchments, provinces and cities, in order to improve the flood control and disaster reduction capability of China, and achieve a huge economic, social and environmental benefits more effectively. 


\section{Acknowledgements}

The research is supported by the Jiangxi Province Flood Forecasting and Regulating System and Flood Control Support System Software Development Project (JZ0205A432013). The authors are very grateful to the reviewer for the in-depth reviews and constructive comments, which greatly helped improve the paper.

\section{Reference}

[1] Rahman, M.M., Goel, N.K., and Arya, D.S. (2012). Development of the Jamuneswari Flood Forecasting System: Case Study in Bangladesh. J. Hydrol. Eng. 17(10), pp.1123-1140.

[2] Li, X.Y., Chau, K.W., and Cheng, C.T., et al. (2006). A Web-based flood forecasting system for Shuangpai Region. Advances in Engineering Software. 37(3), pp.146-158.

[3] Zhao, R.J., Zhang, Y.L., and Fang, L.R., et al. (1980).The Xinanjiang model. Hydrological Forecasting Proceedings Oxford Symposium, IAHS. pp.351-356.

[4] Yao, C., Li, Z.J., and Bao, H.J., et al. (2009). Application of a developed Grid-Xinanjiang model to Chinese watersheds for flood forecasting purpose. Journal of Hydrologic Engineering. 14 (9), pp923934.

[5] Kan, G.Y., Lei, T.J., and Liang, K., et al. (2017).A Multi-Core CPU and Many-Core GPU Based Fast Parallel Shuffled Complex Evolution Global Optimization Approach. Ieee transactions on parallel and distributed systems. 28(2), pp.332-342. 